\title{
La Filmoteca Española, un recurso didáctico para la Historia del Cine y los historiadores de la Educación
}

\author{
The Spanish Film Archive: a didactic resource for the History of \\ Cinema and the historians of Education
}

\author{
Valeriano Durán Manso \\ Departamento de Marketing y Comunicación, Universidad de Cádiz, Jerez de la \\ Frontera (Cádiz), España, valeriano.duran@uca.es
}

\section{Resumen}

Las filmotecas constituyen un espacio esencial para localizar, restaurar, conservar y difundir los archivos audiovisuales. Además, posibilitan su conocimiento y estudio a nivel técnico, narrativo y estético. Debido a su carácter testimonial y artístico, estos archivos poseen un notable valor en áreas tan vinculadas como la Comunicación, la Historia y la Educación. Mediante una metodología cualitativo-descriptiva, este estudio tiene como objetivos reflexionar sobre las funciones de estas instituciones, tomando como estudio de caso a la Filmoteca Española -creada en 1953 durante la dictadura franquista-, y abordar sus posibilidades didácticas para los historiadores. Así, se evidencia que el patrimonio de las filmotecas supone un material de primer orden para la enseñanza de las materias vinculadas a las tres citadas áreas.

Palabras clave: Filmoteca Española. Historia del Cine. Historia de la Educación. Patrimonio audiovisual. Recurso didáctico.

\begin{abstract}
Film archives are an essential space to locate, restore, preserve and disseminate the audiovisual archives. In addition, enable their knowledge and study at a technical, narrative and aesthetic level. Due to its testimonial and artistic character, these archives have a remarkable value in areas as linked as Communication, History and Education. Through a qualitative-descriptive methodology, this study aims to reflect on the functions of these institutions, taking as a case study the Spanish Film Archive -created in 1953 during the Franco dictatorship-, and address their didactic possibilities for historians. Thus, it is evident that the heritage of the film archives is a material of the first order for the teaching of the subjects related to the three mentioned areas.
\end{abstract}

Keywords: Spanish Film Archive. History of Cinema. History of Education. Audiovisual Heritage. Didactic Resource. 


\section{Introducción al patrimonio audiovisual}

Desde su nacimiento en 1895, el cine ha experimentado considerables pérdidas a nivel global. Son numerosos los filmes desaparecidos desde entonces, bien de manera fortuita por los habituales incendios que se originaban durante las exhibiciones -el nitrato de celulosa, uno de los soportes más utilizados, era altamente inflamable-, o intencionada, debido a motivos políticos o económicos. A esto hay que sumar las pérdidas producidas por cambios tecnológicos, como el paso del cine mudo al sonoro a finales de los años veinte, $y$, en menor medida, del blanco y negro al color (VV.AA., 1995). Asimismo, el tiempo supone uno de los principales enemigos del material fílmico, pues, debido a su fragilidad, puede sufrir perforaciones, mutilaciones, contracciones, o la descomposición del soporte; sin duda, un deterioro que incluso desencadena la pérdida del mismo. Otros aspectos que propician su desgaste, sobre todo en los filmes más antiguos, son el sonido y el color, "normalmente, afectado por la temperatura, la polución, la humedad del aire y la luz" (Durán Manso, 2017: 9). Esta situación conlleva la destrucción de la imagen, pero también la pérdida de la narración, del testimonio pasado y de la memoria.

Debido a estas circunstancias, se empezó a tomar conciencia del concepto de patrimonio audiovisual, que al principio abarcó el cine y, posteriormente, incluyó la televisión, la fotografía, los fondos musicales, los archivos radiofónicos y la publicidad. Este término se enmarca dentro del patrimonio cultural, pues a raíz de la creación de la fotografía en el siglo XIX la imagen se convirtió en uno de los elementos culturales más potentes de la historia contemporánea. Esta idea se consolidó con la llegada del cine, es decir, de las imágenes en movimiento, y, posteriormente, con la incorporación del sonido en el periodo mudo -mediante acompañamiento musical-, y en el sonoro. Así, la imagen representa la forma de captar y verificar lo que ha existido, y esto define el valor del cine como patrimonio cultural que remite a una expresión humana y a la sociedad que lo produce. El cine está unido desde su nacimiento a aspectos históricos, artísticos y sociológicos:

Si partimos de la consideración del patrimonio cultural como toda aquella manifestación humana, pasada o presente, tangible o intangible, a la que una colectividad reconoce como representativa de su identidad y vehículo de su memoria (histórica, social, cultural, ideológica), resulta evidente que el cine es uno más de los patrimonios que la sociedad contemporánea debe proteger, conservar, recuperar, investigar y difundir (Rodríguez Ortega, 2011: 16).

El valor patrimonial del cine obtuvo su primer reconocimiento oficial e internacional en 1981, con la Recomendación sobre la salvaguarda y la construcción de las imágenes en movimiento (RSCIM), elaborada por la UNESCO y aprobada en la XXI Sesión de la Conferencia General (Belgrado, 23 septiembre-29 octubre de 1980). Este texto, "que atribuye competencias de los Estados en materia de legislación" (Del Valle Gastaminza, 2013: 115), señalaba catorce pautas que reconocían el valor cultural del cine (UNESCO, 1981: 167). La institución, que decía que "el patrimonio cultural son los bienes que una nación obtiene por herencia" (Hernández Pérez, 2011: 25), se encargaba así de proteger y salvaguardar el 
patrimonio audiovisual. Aunque este concepto varía según la cultura o el país, "en esencia viene a decir que los archivos audiovisuales deben contextualizar las grabaciones, programas y películas con que cuentan reuniendo o protegiendo, según el caso, una serie de objetos, conocimientos y técnicas conexos" (Edmondson, 2004: 24). De forma más precisa, el autor indica que este patrimonio abarca los siguientes ámbitos:

- Las grabaciones cinematográficas, sonoras o televisivas que incluyan imágenes en movimiento, tanto en soporte fílmico como digital, es decir, la película.

- Los objetos materiales e inmateriales relativos a los documentos audiovisuales, a nivel técnico, industrial, histórico y cultural, como guiones, fotografías, carteles, vestuarios, o los textos periodísticos y aquellos vinculados con la censura.

- El mantenimiento de técnicas en desuso relacionadas con la producción, la reproducción o la exhibición del cine.

- El material no literario o gráfico, como fotografías, manuscritos, diapositivas o mapas, que están relacionados con la labor cinematográfica.

Así, en el patrimonio audiovisual conviven ambas esferas: la artística, correspondiente al estilo, lo visual o la narrativa, y la testimonial, que se aproxima a la realidad histórica y social mediante las imágenes transmitidas. Por ello, el audiovisual está unido a una notable dimensión cultural, tanto en lo relativo a la alta cultura o a su carácter popular, como al valor cultural que posee como documento histórico o social. A este respecto, se puede reconocer que "el cine como documento de la realidad, como reflejo de la vida, como información, nace con los Lumière" (Del Valle Gastaminza, 2013: 112). Por otra parte, se puede diferenciar entre patrimonio fílmico y patrimonio cinematográfico. El primero hace referencia al conjunto tangible de películas que se deben preservar por su lugar en la historia del cine, su valor como reflejo de la sociedad o por representar un momento histórico de especial relevancia, mientras que el segundo, reconocido en 2004, tiene una dimensión más amplia al incluir todos aquellos elementos que constituyen el proceso cinematográfico, desde la maquinaria al vestuario, los carteles o los estudios (Rodríguez Ortega, 2011). Tras el centenario del cine en 1995, instituciones como la UNESCO y la Unión Europea han desarrollado iniciativas sobre el valor patrimonial del séptimo arte que han tenido una notable repercusión cultural y social.

\section{Aproximación a la aparición de las primeras filmotecas}

Para poder comprender la importante labor que estas instituciones ejercen, es necesario tener en cuenta dos aspectos básicos. El primero pone de relieve que "ni los materiales ni los procesos de elaboración de una película fueron pensados para su conservación a largo plazo" (Piqueras, 1995: 8), mientras que el segundo 
manifiesta que "conforme los avances técnicos y artísticos del cine se van acrecentando, las viejas películas pierden todo su valor para la industria del espectáculo, dejan de ser una mercancía rentable y se destruyen para el aprovechamiento de sus desechos" (Soria, 2005: 21-22). Esto adquiere valor al reflexionar sobre el papel del cine como testigo de la evolución de la sociedad y como expresión artística contemporánea, debido a la toma de conciencia de su carácter patrimonial, su preservación y, en definitiva, su oportuna difusión.

Desde estas consideraciones, y a pesar de diversos intentos para la creación de archivos cinematográficos a finales del siglo XIX (Hernández Pérez, 2011), las iniciativas para la conservación de películas no se desarrollaron hasta la llegada del sonoro en 1927, lo que indica que buena parte de la producción muda desapareció. Así, las primeras filmotecas aparecieron en la década de los 30 ante la necesidad de preservar los filmes silentes que habían perdido valor comercial frente al sonoro, pero que habían adquirido un valor histórico-social (Rodríguez Ortega, 2011). De esta manera, Europa y Estados Unidos acogieron los centros pioneros en esta materia, tanto públicos como privados. En 1933 nació en Estocolmo el Svenska Filmsandfundet Arkiv, por iniciativa privada; en 1934 el ministro de Propaganda alemán, Joseph Goebbles, inauguró el Reichfilmarchiv; en 1935 aparecieron el National Film Archive de Londres y el archivo de cine del Museum of Modern Art (MOMA) de Nueva York; y en 1936 se instituyó en París la Cinémathèque Française. En 1938 los cuatro últimos fundaron la Federación Internacional de Archivos Fílmicos (FIAF) en la capital francesa, que, a causa de la II Guerra Mundial no inició su labor hasta 1946. Del Valle Gastaminza (2013: 114) recoge sus propósitos:

1. Favorecer la recuperación y la conservación de todas las películas, consideradas como obras de arte y/o como documentos históricos.

2. Facilitar la recuperación y la conservación de los materiales de documentación de todo tipo relacionados con las películas.

3. Promover en todos los países la creación y el desarrollo de archivos de filmes consagrados a la salvaguarda del patrimonio cinematográfico nacional e internacional.

4. Desarrollar la cooperación entre sus miembros y asegurar la disponibilidad de las películas y de los documentos a nivel internacional.

5. Promover el arte y la cultura del cine y las investigaciones históricas sobre todos los aspectos del cine.

La FIAF posibilitó el desarrollo de filmotecas a nivel mundial, como sucedió en España, cuya Filmoteca Nacional nació en 1953 -como se verá más adelante-, y se integró en esta institución internacional tres años después. Asimismo, el compromiso de la UNESCO con el valor cultural del cine marcó un notable aumento del interés por los archivos audiovisuales en la década de los 80 , pues con el desarrollo del cine posmoderno se empezó a tomar conciencia de que "las películas antiguas son joyas que resumen y atesoran la historia y costumbres de todo un pueblo", y que "el cine recupera y conserva para siempre todas esas imágenes" (Feiner, 2004: 12). De esta manera, en la actualidad, la FIAF, cuya sede se encuentra en Bruselas, acoge más de 150 filmotecas de 77 países distintos. 
A este respecto, las leyes nacionales e internacionales sobre la protección y el reconocimiento del patrimonio audiovisual proliferaron a raiz de la Recomendación sobre la salvaguarda y la construcción de las imágenes en movimiento, de la UNESCO, en 1981. Esta declaración ejerció una notable influencia en el desarrollo de leyes en diferentes países para proteger los archivos fílmicos, como España. A pesar de que durante el franquismo (1939-1975) se desarrollaron varias iniciativas que protegían la producción cinematográfica nacional, especialmente a partir de los años 60 , la principal regulación legislativa de la protección fílmica se produjo en los 80 , tras la reciente instauración democrática. Además, la entrada del país en las instituciones europeas, en 1986, contribuyó notablemente a que se beneficiara de las políticas comunitarias sobre la materia. A continuación, se muestra una tabla sobre las iniciativas más relevantes de la UNESCO y las desarrolladas en España en las últimas décadas, es decir, durante un período de casi cuarenta años:

Tabla 1: Legislación sobre el patrimonio audiovisual

\begin{tabular}{|c|c|c|}
\hline & UNESCO & España \\
\hline Años 80 & $\begin{array}{l}\text { - Recomendación sobre la } \\
\text { salvaguarda y la construcción de } \\
\text { las imágenes en movimiento } \\
\text { (RSCIM) (Belgrado, 23-09/ 29-10- } \\
\text { 1980): } \\
\text { - Reconoce el valor patrimonial } \\
\text { cine } \\
\text { - Tiene una considerable } \\
\text { repercusión a nivel mundial } \\
\text { - Supone una toma de } \\
\text { conciencia en torno al tema }\end{array}$ & $\begin{array}{l}\text { - Ley 16/1985, del Patrimonio } \\
\text { Histórico Español (LPHE): integra al } \\
\text { cine como patrimonio documental y } \\
\text { bibliográfico } \\
\text { - Real Decreto } 7 / 1987,10 \text { de enero: } \\
\text { - Aborda la actividad y la } \\
\text { organización de las } \\
\text { filmotecas } \\
\text { - Define que el concepto de } \\
\text { patrimonio cinematográfico } \\
\text { comprende todos los } \\
\text { aspectos vinculados al cine }\end{array}$ \\
\hline Años 90 & $\begin{array}{l}\text { - 1995: Centenario del Cine (París): } \\
\text { - Se pide su conservación y } \\
\text { recuperación } \\
\text { - Concienciación de la pérdida } \\
\text { que conlleva la fragilidad de } \\
\text { los soportes fílmicos }\end{array}$ & $\begin{array}{l}\text { - Se empiezan a aplicar las primeras } \\
\text { normativas de la Unión Europea }\end{array}$ \\
\hline $\begin{array}{l}\text { Años } \\
2000\end{array}$ & $\begin{array}{l}\text { - 27/10/2007: Primer Día Mundial } \\
\text { del Patrimonio Audiovisual }\end{array}$ & $\begin{array}{l}\text { - Se aplican también las normativas } \\
\text { de la Unión Europea }\end{array}$ \\
\hline Años 10 & $\begin{array}{l}\text { - 2013: La Federación Internacional } \\
\text { de Archivos Fílmicos (FIAF) solicita } \\
\text { a la UNESCO la declaración } \\
\text { patrimonial del cine analógico }\end{array}$ & $\begin{array}{l}\text { - Se aplican también las normativas } \\
\text { de la Unión Europea }\end{array}$ \\
\hline
\end{tabular}

Fuente: Elaboración del autor. 
Algunas de las principales funciones que tienen las filmotecas son la localización, la conservación, la restauración y la difusión de los archivos audiovisuales. Esto convierte a las filmotecas en espacios que posibilitan el conocimiento, el análisis y el estudio del propio producto fílmico, o incluso televisivo, fotográfico y sonoro. Aquí se incluyen las entrevistas, reportajes o programas sobre un estreno emitidos en la pequeña pantalla, las fotografías de los rodajes o las bandas sonoras de las películas, entre otros. Asimismo, estas instituciones actúan como nexo entre el patrimonio fílmico y la sociedad:

Los grandes avances de la humanidad son fruto de la educación, del conocimiento, de la investigación y, sobre todo, del compromiso del ser humano para conservar parte de su historia. Una idea es importante cuando se pone en práctica, y más cuando alguien la plasma en un libro y se puede utilizar siglos después. Si nadie la escribe, si nadie la conserva en una biblioteca, si nadie hace un esfuerzo para que otras personas la conozcan, esa idea termina por desaparecer. El compromiso para que llegue a otras generaciones esa idea es lo que permite que avance la sociedad (Marcos Recio, 2013: 12).

Aunque las filmotecas más relevantes son las de carácter público que están presentes en cada país o región, como sucede en España, algunas privadas pertenecientes a museos o fundaciones también desarrollan una significativa labor. Asimismo, otros organismos de tipo público, como las Universidades, las bibliotecas y los archivos, tanto nacionales como temáticos o municipales (Edmonson, 2004), desempeñan un notable trabajo en la localización y difusión de materiales fílmicos. Sin embargo, son las filmotecas las que realizan una función más específica al incluir los complejos, pero, sin duda, necesarios trabajos de restauración.

\section{La Filmoteca Española}

La Filmoteca Nacional de España se fundó el 13 de febrero de 1953 durante la dictadura de Francisco Franco (1939-1975), el año que el país entró en la UNESCO. Apareció al hilo de las pioneras de carácter nacional surgidas en la década de los 30 en varios países europeos, aunque con un retraso de veinte años. Su creación significó un apoyo para la conservación del audiovisual español, y, de hecho, sus fondos están compuestos en su mayoría por películas españolas, pues en 1964 se fijó que había que depositar en la filmoteca obligatoriamente una copia de todas las que habían recibido una subvención de la Dirección General de Cinematografía (Prado, 2005). Esto ha permitido localizar y conservar la producción cinematográfica nacional desde entonces $y$, además, ha evitado la pérdida de numerosos títulos. Aunque al principio se ubicó en la sede del NO-DO, en la calle Joaquín Costa de Madrid, la filmoteca ha ocupado varios espacios de la capital hasta la inauguración de su sede definitiva en 2002, en el Palacio de Perales, situado en el centro. Este traslado supuso una notable ampliación del espacio de almacenamiento de los fondos fílmicos, la colección de aparatos de cine y el servicio de documentación, así como un incremento del espacio de acceso de los investigadores a los fondos de la biblioteca y del archivo gráfico y cinematográfico (Prado, 2005). 
La filmoteca cuenta con otras dos dependencias. Una de ellas es el Cine Doré, una sala histórica que data de 1912 y que fue recuperada en 1989 como espacio fijo dedicado a la exhibición y la difusión. Muy próximo al anterior, se ha convertido en un lugar "donde se unen el encuentro, el visionado, el debate y la divulgación, y que posee una librería especializada" (Durán Manso, 2017) dedicada a diversos aspectos del cine, donde hay desde libros a revistas científicas, guiones y carteles. El tercer espacio es el Centro de Conservación y Restauración, que se inauguró en 2012 en la Ciudad de la Imagen, en la localidad madrileña de Pozuelo de Alarcón. En la década de los 80 se advirtió la necesidad de tener un lugar propio para conservar todos los materiales de la filmoteca, que estaban repartidos por distintos almacenes, y así mantener mejor sus características fotográficas y sonoras. Este complejo cuenta con un archivo destinado a las películas de nitrato de celulosa -las más inflamables-, que es subterráneo para poder garantizar las condiciones óptimas para almacenar las latas de celuloide, y cuenta también con unas condiciones climáticas concretas para el almacenamiento de los filmes en materiales más seguros, como el acetato de celulosa o el poliéster. De esta manera, "la idea central del diseño del archivo consistió en establecer y controlar los parámetros de las cuatro variables básicas que fundamentan la estrategia de conservación: temperatura, humedad relativa, ventilación y estabilidad" (De la Fuente, 2015: 75).

Esto constata que la filmoteca, cuyo objetivo es custodiar el patrimonio fílmico español, ejerce las tres funciones principales que distinguen a las filmotecas de otros espacios dedicados a las tareas de registro o catalogación de material-como las bibliotecas-, la localización, la recuperación o restauración y la conservación (Hernández Pérez, 2011), además de labores de documentación, catalogación y difusión. A este respecto, se puede afirmar que la conservación ocupa un lugar esencial, y, por ello, existe una necesidad de recuperar y proteger los archivos audiovisuales para evitar su deterioro -debido a la fragilidad de los soportes-, y, además, perpetuar la memoria presente en ellos. En este sentido, "que existan las filmotecas hace posible que podamos encontrar y que podamos recuperar parte de nuestra memoria colectiva" (Rodríguez Ortega, 2011: 23).

La misión de la filmoteca, que en 1982 pasó a llamarse Filmoteca Española, adquirió un gran impulso con la llegada de la democracia en 1975. Su labor propició la creación de otras similares en las recién creadas comunidades autónomas, que, a su vez, la tomaron como modelo para la conservación del cine, en este caso del realizado o filmado en cada región. Por ello, no fue hasta los 80 cuando las filmotecas experimentaron en España un gran crecimiento y surgieron políticas enfocadas al patrimonio fílmico. No obstante, existían ya la Filmoteca Vasca (1978); la Filmoteca de Catalunya (1981), que surgió a raíz de una delegación de la Filmoteca Nacional en 1972; o la Filmoteca de Zaragoza (1981). Actualmente, otras de tipo regional son la Filmoteca Canaria (1984); la Filmoteca de Andalucía (1989); el Centro Galego de Artes da Imaxe (1991); la Filmoteca de Castilla y León (1991); la Filmoteca de Asturias (1996); el Arxiu del So i la Imatge (1998), en Palma; el Instituto Valenciano de Cinematografía (1998); la Filmoteca de Albacete (2001), la Filmoteca de Cantabria (2001); la Filmoteca de Extremadura (2003); y la Filmoteca Regional Francisco Rabal (2004), en Murcia (Santamarina, 2005). 


\section{Posibilidades de la Filmoteca Española para la Historia del Cine y los historiadores de la educación}

Partiendo de la idea de que lo que no se halla, conserva y difunde no tiene visibilidad $y$, en consecuencia, se desconoce, las filmotecas constituyen los baluartes del patrimonio fílmico. Por ello, "es preciso localizar, identificar y recuperar materiales perdidos, es preciso restaurarlos 0 , al menos, detener su deterioro y es preciso, por encima de todo, preservarlos de todos los posibles daños que les puedan afectar para después exhibirlos y difundirlos" (Del Valle Gastaminza, 2013: 122). Así, debido a su dimensión artística y testimonial, el cine tiene un valor importante en tres ámbitos estrechamente vinculados: la Comunicación, la Historia y la Educación. La relación entre el celuloide y los medios, así como su papel en la historia por su valor como documento, le otorga al séptimo arte un lugar relevante para la formación y el estudio de estas áreas. Además, el cine se debe tomar desde la mirada de los historiadores, pues "ofrece imágenes que sociológicamente ilustran las preocupaciones, las costumbres, los objetos y las formas de entender la vida de una época" (Caridad et al., 2011: 15). En resumen, se trata de "un medio que guarda importantes riquezas para el conocimiento futuro de la sociedad, ya que en sus películas se puede estudiar [...] una parte de la historia" (Marcos Recio, 2013: 19).

La difusión se covierte así en una función primordial de la filmoteca. Resulta necesario interiorizar que el cine refleja, representa o reconstruye una realidad del presente 0 , normalmente, del pasado, y esto permite conectar con los imaginarios colectivos y con la creación y perpetuación de la memoria. Además, esta difusión no solo se enfoca a los espectadores más mayores, para que se reencuentren con el cine del ayer, es decir, el que marcó su juventud y ha marcado su trayectoria vital, sino también a las nuevas generaciones. Es necesario que los jovenes conozcan los títulos fundamentales de las diferentes cinematografías, las obras desconocidas de los autores más relevantes o las películas de las corrientes estéticas que han hecho posible la evolución de la Historia del Cine, pues esto fomenta la necesaria reflexión sobre las narrativas, los procesos y las tecnologías del pasado para poder entender el presente fílmico. Aprender con el cine y viendo cine pone de relieve la importante labor educativa, social y cultural que la función de difusión tiene en las filmotecas; una labor que debe ser aprovechada y asimilada por los investigadores, los docentes y los historiadores para la transmisión y el conocimiento del pasado a partir del séptimo arte, tanto de forma directa como aplicada en las materias.

En esta labor de difusión, la Filmoteca Española, así como otras de entidad regional, tiene un firme compromiso con la transmisión de la cultura. No sólo conserva y restaura, sino que expande el patrimonio cinematográfico para promover su conocimiento mediante iniciativas que comprenden desde ciclos de cine, retrospectivas y el reestreno de filmes recién recuperados o restaurados, a talleres, seminarios con expertos o presentaciones, que ponen en valor unos fondos que la sociedad debe conocer al formar parte de ella. La programación del Cine Doré 
acoge más de 1.200 proyecciones al año, que redescubre a los pioneros del cine, a los clásicos y a los directores contemporáneos; promociona el cine español con títulos poco conocidos u olvidados, así como el cine latinoamericano o el de países con escasa presencia en los cauces de la exhibición española; y fomenta las cinematografías de vanguardia (Santamarina, 2005). El cometido cultural, educativo y formativo de la filmoteca entronca con los intereses pedagógicos de los historiadores de la educación, de manera que llevar este patrimonio a los centros de enseñanza y, sobre todo, a la Universidad, es vital para que los jóvenes puedan conocer su pasado fílmico y comprender mejor la realidad de su presente. Sin duda, el patrimonio cinematográfico "se comunica, se aprende, se interioriza, se vive y se siente. Lo necesitamos para saber quiénes somos, para saber qué somos" (Álvarez Domínguez, 2016: 30).

Por otra parte, esta institución cuenta con una serie de colecciones y materiales de gran interés para los docentes. En primer lugar, destaca su biblioteca especializada, pública, gratuita y principalmente enfocada al trabajo de críticos, investigadores e historiadores; su archivo gráfico, compuesto por más de medio millón de fotografías vinculadas con el cine, carteles, programas de mano o guías de películas; la fonoteca, que atesora más de 6.000 documentos sonoros desde los años 20, y en diversos soportes; y, por último, la Colección, que se ha creado para el futuro Museo del Cine y que reúne más de 22.000 piezas relacionadas con la fotografía, el denominado precine y el cine, como daguerrotipos, linternas mágicas y proyectores, respectivamente (Santamarina, 2005). Asimismo, ejerce una notable labor editorial al editar y coeditar libros especializados -junto con el Festival de Cine de San Sebastián, entre otros certámenes de prestigio-, y cuenta con la colección Cuadernos de la Filmoteca para la divulgación de textos sobre la conservación y la restauración, filmografías de cineastas, monografías o catálogos.

El material audiovisual supone un atractivo recurso didáctico para una asignatura como Historia de la Educación. A través del cine, los alumnos pueden conocer las vidas de los pedagogos, las leyes educativas o el modelo de enseñanza de cada etapa histórica y política, así como la relación entre los profesores y los alumnos, la visión de la educación en el seno de la familia o las posibilidades de la educación para el cambio social, especialmente en los periodos convulsos, como reflejan tanto los filmes documentales como de ficción. A este respecto, "lo mejor que puede hacer la escuela hoy es hablar ante todo de las películas como obras de arte y de cultura. Dar a los alumnos otros puntos de referencia y aproximarse a las películas en confianza" (Bergala, 2007: 49), y, por ello, las filmotecas constituyen unas grandes aliadas para los historiadores. Asimismo, estas instituciones se han convertido en un espacio para la memoria, pues las películas representan, reflejan y reconstruyen realidades pasadas, y poseen una dimensión cultural y un valor patrimonial que resultan necesarios a nivel docente. Esto indica que se puede conocer la historia a partir de las imágenes y el audiovisual y que, además, el cine contribuye al enriquecimiento cultural y crítico del alumnado. Por este motivo, "para los historiadores, nada reflejará la sociedad en que vivimos como los documentales, las noticias, las producciones audiovisuales de vanguardia, las independientes, las 
industriales, las científicas, los anuncios publicitarios... todo esto forma también parte de la memoria colectiva del siglo XX y XXI" (Hernández Pérez, 2011: 24).

Sin duda, la Filmoteca Española ofrece muchos y diversos recursos para los docentes e investigadores de estas área de conocimiento. Por ello, los historiadores de la educación deben tener en esta institución un referente para la búsqueda de materiales -tanto a nivel científico como para la preparación de las clases-, el planteamiento de prácticas con los alumnos, la organización de talleres y exposiciones temáticas, o el análisis narrativo a través de los visionados de filmes relevantes por su calidad o complejo acceso. En este sentido, también sería muy interesante para estos docentes el fomento de las relaciones entre la filmoteca y los museos pedagógicos (Álvarez Domínguez, 2016), pues así se podría, y conseguiria, mirar al pasado histórico-educativo desde el patrimonio cinematográfico; sin duda, todo un reto que aunaría el carácter testimonial de ambas instituciones.

\section{Reflexiones finales}

- En sus 122 años de historia, el cine ha mostrado cómo es la sociedad, el contexto político y económico, o la educación y la cultura, permitiendo enmarcar las películas en su periodo concreto y, a la vez, posibilitando que la profundización en ellas ayude al conocimiento y el estudio de ese periodo histórico determinado. Por ello, el cine se considera un importante medio para la construcción de contextos y para la comprensión de los mismos en las más diversas áreas. Con ello, se afianza el valor de identidad entre lo que aparece representado en la gran pantalla y la sociedad que visiona y contempla esa representación. Esta dimensión tiene un importante valor tanto en el cine documental -que está más vinculado al carácter testimonial del celuloide-, como en el de ficción producido en cada país.

- Las diferentes cinematografías, géneros narrativos, estilos y vanguardias han contribuido a la construcción de un patrimonio audiovisual que se convierte en un objeto de estudio y análisis para conocer e investigar el pasado. El cine tanto de forma fiel, maquillada, idealizada o propagandística-, constituye el reflejo de una realidad concreta, y esto aporta una información muy valiosa del momento y el contexto en el que una película fue estrenada. Por ello, este material posee una dimensión investigadora que va más allá del carácter documental o de ocio para el que el séptimo arte fue concebido en principio.

- Las filmotecas se erigen como espacios comprometidos con la recuperación, la conservación, la restauración y la difusión de los archivos fílmicos que, a su vez, garantizan la perpetuación de la memoria y la cultura audiovisual. La necesidad de recuperar y proteger los archivos audiovisuales para evitar su deterioro -debido a la fragilidad de los soportes-, resulta fundamental también en la conservación de la memoria, aspecto para el que las filmotecas, como, en este caso, la Filmoteca Española, tienen un gran compromiso. Además, la 
labor de difusión permite la transmisión de esta memoria a la sociedad; sin duda, una tarea esencial para el conocimiento del pasado.

- Las obras audiovisuales recopiladas y conservadas en las filmotecas constituyen un material fundamental para la enseñanza de materias vinculadas a áreas como la Comunicación, la Historia y la Educación. El cine supuso una revolución en el desarrollo de las artes visuales, y su desarrollo ha posibilitado el estudio de temas y aspectos pertenecientes al ámbito de las Humanidades y de las Ciencias Sociales. En el caso de la Educación, donde el material audiovisual representa un atractivo recurso didáctico para la enseñanza de la Historia de la Educación, los archivos fílmicos se antojan necesarios para el estudio de la disciplina desde una perspectiva históricoeducativa. Así, las filmotecas se erigen como un espacio de memoria para los historiadores, pues los filmes son un reflejo, una representación o una reconstrucción de una realidad pasada y de un hecho concreto.

- Los historiadores de la educación tienen en la Filmoteca Española un recurso didáctico que les ofrece diversas posibilidades, a nivel docente e investigador, y les proporciona una interesante mirada al pasado histórico-educativo. A pesar de que apareció con retraso con respecto a las consideradas pioneras -surgidas en la década de los 30 en países como Suecia, Alemania, Francia, Reino Unido o Estados Unidos-, su nacimiento significó un apoyo decisivo para la conservación del audiovisual español. Esta misión adquirió un notable impulso con la llegada de la democracia en 1975, y, asimismo, posibilitó el desarrollo y la estructuración de la filmoteca en varios espacios, y la creación de otras similares en algunas regiones españolas. Estas recientes filmotecas autonómicas son, a su vez, espacios interesantes para la salvaguarda del património fílmico de carácter regional $-\mathrm{y}$, por ello, tienen un importante valor en el estudio de la historia del cine y del pasado escolar en las distintas zonas españolas-, y para conocer su particular idiosincrasia y la aportación de los cineastas que reflejaron la vida y la educación en sus propios entornos.

\section{Referencias}

Álvárez Domínguez, P. (2016). "Los Museos Pedagógicos en España: actualidad y perspectivas de futuro", en Álvarez Domínguez, P. Los Museos Pedagógicos en España. Entre la memoria y la creatividad. Gijón/Sevilla: Ediciones Trea/ Editorial Universidad de Sevilla, pp. 21-32.

Bergala, A. (2007). La hipótesis del cine. Pequeño tratado sobre la transmisión del cine en la escuela y fuera de ella. Barcelona: Laertes.

Caridad, M., Hernández, T., Rodríguez, D. y Pérez, B. (2011). Documentación audiovisual. Madrid: Editorial Síntesis.

De la Fuente, M. (2015). "El centro de conservación y restauración de la filmoteca española". Patrimonio cultural de España, 10, pp. 73-82. 
Del Valle Gastaminza, F. (2013). "Patrimonio cinematográfico", en Marcos Recio, J. C. (coord.). Gestión del patrimonio audiovisual en medios de comunicación. Madrid: Editorial Síntesis, pp. 111-129.

Durán Manso, V. (2017): "El cine como patrimonio cultural: el caso de la Filmoteca Española”. Ridphe_R Revista Iberoamericana do Patrimônio Histórico-Educativo, Vol. 3, №. 1, ene./jun., pp. 7-33. Recuperado de: http://ojs.fe.unicamp.br/index.php/RIDPHE-R/article/view/7743/6517

Edmondson, R. (2004). Filosofía y principios de los archivos audiovisuales. París: UNESCO, (Cl, 2004/WS/2). Recuperado de: http://unesdoc.unesco.org/images/0013/001364/136477s.pdf.

Feiner, M. (2004). ¡Torero! Los toros en el cine. Madrid: Alianza Editorial.

Hernández Pérez, T. (2011). "La documentación audiovisual”, en Caridad, M., Hernández, T., Rodríguez, D. y Pérez, B. Documentación audiovisual. Madrid: Editorial Síntesis, pp. 19-43.

Marcos Recio, J. C. (coord.) (2013). Gestión del patrimonio audiovisual en medios de comunicación. Madrid: Editorial Síntesis.

Piqueras, M. J. (1995). "La fragilidad de la memoria", en VV.AA. La imagen rescatada. Recuperación, conservación y restauración del Patrimonio Cinematográfico. Valencia: Filmoteca Generalitat Valenciana, pp. 7-9.

Prado, J. M. (2005). "Claves para un cincuentenario", en Santamarina, A. Filmoteca Española. Cincuenta años de historia. Madrid: Filmoteca Española, Instituto de la Cinematografía de las Artes Audiovisuales y Ministerio de Cultura, pp. 9-18.

Rodríguez Ortega, N. (2011). "El patrimonio fílmico y cinematográfico. Cuestiones para una reflexión abierta”, en Sauret Guerrero, T., Ruiz San Miguel, J., Gómez Gómez, A. J., y Chaves Guerrero, E. I. (ed.). El cine español: arte, industria y patrimonio cultural. Málaga: Ministerio de Cultura, Instituto de Cinematografía y de las Artes Audiovisuales (ICAA) y Servicio de Publicaciones de la Universidad de Málaga, pp. 15-28.

Santamarina, A. (2005). Filmoteca Española. Cincuenta años de historia. Madrid: Filmoteca Española, Instituto de la Cinematografía de las Artes Audiovisuales (ICAA) y Ministerio de Cultura.

Soria, F. (2005). "Los primeros treinta años: una larga carrera de obstáculos", en Santamarina, A. Filmoteca Española. Cincuenta años de historia. Madrid: Filmoteca Española, Instituto de la Cinematografía de las Artes Audiovisuales (ICAA) y Ministerio de Cultura, pp. 21-57.

Unesco (1981). Actas de la Conferencia General. 21.a reunión Belgrado, 23 de septiembre-28 de octubre de 1980. Volumen 1 Resoluciones. París: UNESCO Recuperado de http://unesdoc.unesco.org/images/0011/001140/114029s.pdf

VV.AA. (1995). La imagen rescatada. Recuperación, conservación y restauración del Patrimonio Cinematográfico. Valencia: Filmoteca Generalitat Valenciana. 